\title{
Autoimmune Hepatitis-Primary Biliary Cirrhosis: Overlap Syndrome Concomitant with Unexpected Myasthenia and Thymoma
}

\author{
Mahfoudhi Madiha*, Mamlouk Habiba, Turki Sami, Kheder Adel \\ Department of Internal Medicine, A. Charles Nicolle Hospital, Tunis, Tunisia \\ Email: ${ }^{*}$ madiha mahfoudhi@yahoo.fr
}

Received 20 February 2015; accepted 12 March 2015; published 18 March 2015

Copyright $@ 2015$ by authors and Scientific Research Publishing Inc.

This work is licensed under the Creative Commons Attribution International License (CC BY).

http://creativecommons.org/licenses/by/4.0/

(c) ()

\section{Abstract}

The myasthenia gravis is an autoimmune disease which can be associated frequently with a thymoma and also with autoimmune pathologies. We report the case of a 64-year-old man affected an overlap syndrome corresponding to the association of autoimmune hepatitis (AIH) and primary biliary cirrhosis (PBC). He also presented concomitant myasthenia gravis and thymoma. The physical examination notes only a disturbed voice. The liver tests showed: alkaline phosphatase $600 \mathrm{U} / \mathrm{l}$, alanine aminotransferase $1280 \mathrm{U} / \mathrm{l}$, and aspartate aminotransferase $985 \mathrm{U} / \mathrm{l}$. Viral serologies of hepatitis were all negative, as well as antinuclear, antimitochondrial and antismooth muscle antibodies. The diagnosis of an overlap syndrome was posed according to the biological and hepatic histhological results. An associated myasthenia was confirmed by the results of the EMG and the positivity of the anti-acetylcholine receptor antibody. A chest CT revealed a thymoma. The treatment consisted of ursodeoxycholic acid, prednisone, azathioprine and pyridostigmine. And the patient improved his voice and the liver function. Thymectomy was practiced without incidents.

\section{Keywords}

Overlap Syndrome, Myasthenia, Thymoma

\section{Introduction}

The myasthenia gravis is an autoimmune disease related to the production of anti-acetylcholine receptor antibodies leading to an excessive tiredness of skeletal muscle. A thymoma is frequently associated with myasthenia.

\footnotetext{
"Corresponding author.
}

How to cite this paper: Madiha, M., Habiba, M., Sami, T. and Adel, K. (2015) Autoimmune Hepatitis-Primary Biliary Cirrhosis: Overlap Syndrome Concomitant with Unexpected Myasthenia and Thymoma. Open Journal of Clinical Diagnostics, 5, 20-23. http://dx.doi.org/10.4236/ojcd.2015.51004 
Several autoimmune diseases can be concomitant to this pathology. Once the myasthenia gravis diagnosis is posed, an exhaustive research of autoimmune associated diseases is compulsory to have complete follow up of the patient [1]. We report the case of a 64-year-old man presenting an autoimmune hepatitis (AIH)—primary biliary cirrhosis (PBC) or an overlap syndrome concomitant with unexpected myasthenia gravis and thymoma. We highlight the exceptional aspect of this association and the necessity of an exhaustive research of autoimmune diseases in presence of a thymoma.

\section{Case Presentation}

We report the case of a 64-year-old man. He had no special pathological history. The physical examination noted only a disturbed voice. There was no muscle deficiency. The abdominal examination didn't reveal a hepathomegaly or a collateral circulation. He had no physical signs of a hepatic insufficiency or a portal hypertension. The cardiac, respiratory and neurological exams were without anomalies.

The liver tests showed: alkaline phosphatase: $600 \mathrm{U} / \mathrm{l}$, bilirubin: $21 \mathrm{umol} / \mathrm{l}$, alanine aminotransferase: 1280 $\mathrm{U} / \mathrm{l}$, and aspartate aminotransferase: $985 \mathrm{U} / \mathrm{l}$. Viral serologies of hepatitis A, B, and C were all negative, as well as antinuclear, antimitochondrial and antismooth muscle antibodies. A hepatic biopsy found a lymphocytic destructive cholongitis and a peri-portal and lobular inflammatory lesions. The Ig $\mathrm{G}$ level exceeded twice the normal level. The diagnosis of an overlap syndrome was posed. An associated myasthenia was confirmed by the results of the EMG and the positivity of the anti-acetylcholine receptor antibody. A chest CT revealed a thymoma.

The treatment consisted of ursodeoxycholic acid, prednisone, azathioprine and Pyridostigmine, given orally.

And the patient improved his voice and the liver function. After a month of treatment, the liver enzymes became in the normal interval.

Thymectomy was practiced without incidents and anatomopathological examination didn't mention signs of malignancy.

\section{Discussion}

The myasthenia is an auto-immune disease which can present in atypical features especially in elderly patients inducing a diagnostic lateness.

The diagnostic of myasthenia must be researched even in the absence of muscle weakness. Thus, our case highlights the importance of investigating an isolated voice disturbance. The ORL examination completed by a laryngoscopy can be normal, so an EMG and a research of anti-acetylcholine receptor antibody are indicated to confirm an unexpected myasthenia.

An early diagnosis permits to avoid many severe complications especially acute respiratory failure [2].

An expected case was published at 2004 demonstrating the association of atypical myasthenia, manifesting by a dysphagia, to a PBC, an ulcerative colitis and a vitiligo [1].

Once the diagnosis of a myasthenia is done, an exhaustive research of an autoimmune associated pathology must be carried out. The presence of a thymoma is characterized by the association of three autoimmune diseases or more (Basedow disease, myositis, AIH, PBC...) [3] [4]. This is may be due a dysfunction of T lymphocytes. Anomalies of $\mathrm{T}$ regulators explaining the pathogeny of many autoimmune pathologies would be more frequent in the presence of a thymoma.

The thymus is a member which is involved in the development of the immune system. The thymus is not always expanded in patients with myasthenia gravis but the microscopic examination often shows there are more cells than normal (called hyperplasia), especially when myasthenia gravis is present for several years. Although most thymomas are benign, they are usually surgically removed because of a possible risk of malignancy. If a large portion of the thymus is removed surgically, the symptoms of myasthenia gravis usually decrease and in some cases disappeare completely.

The myasthenia was rarely described in concomitance with auto-immune liver diseases. It can be associated to an AIH [5] [6] or a PBC [7] [8].

The association of myasthenia and PBC was especially noted after the D penicillamine prescription in a case of a PBC. This association was less rare in absence of this prescription [9].

Only one case of a myasthenia associated to a sclerosing cholangitis was published [10].

The practice of hepatic tests are compulsory during the follow up of a myasthenia in order to detect an au- 
toimmune hepatopathy; since except many no specific signs as asthenia, arthralgia, myalgia, there are any clinical manifestation that orientates to this diagnosis.

The association of the myasthenia to both the AIH and PBC known as "overlap syndrome" is extremely rare. This syndrome has no specific signs. It can be asymptomatic or revealed by a fatigue or an arthralgia [11].

There are no standard criteria to confirm the overlap syndrome. The most adopted criteria are those of International AHI Group [12] and the simplified criteria for the AIH [13], consisting of biological, immunological and histhological criteria. The criteria proposed by Chazouilleres et al. [14] are specific, but their sensitivity is not demonstrated.

No standard treatment is available in case of an overlap syndrome (PBC and AIH). The clinical course of this association and response to treatment is variable.

Oral corticosteroid therapy sometimes associated with azathioprine will be prescribed if the signs of AHI are predominant [11].

However, patients having a predominant PBC feature respond to oral ursodeoxycholic acid in combination with oral glucocorticoids [11].

In case of the association of this syndrome to a myasthenia, the glucocorticoid is efficient in each disease.

The outcome of this association depends on the response to coticotherapy, pyridostigmine, azathioprine and if necessary ursodesoxycholic acid [7] [8].

\section{Conclusion}

The clinical presentation of the myasthenia is heterogeneous and is often atypical in elderly persons inducing a lateness of the diagnostic delay. An autoimmune associated disease, such as autoimmune liver diseases, must be researched even if the patient is asymptomatic.

\section{Conflict of Interests}

The authors declare that there is no conflict of interests regarding the publication of this paper.

\section{References}

[1] McCann, P. and Pramanik, A. (2004) Dysphagia and Unexpected Myasthenia Gravis Associated with Primary Biliary Cirrhosis, Ulcerative Colitis and Vitiligo. Journal of the American Geriatrics Society, 52, 1407-1408. http://dx.doi.org/10.1111/j.1532-5415.2004.52379 7.x

[2] van de Warrenburg, B.P., Hengstman, G.J., Vos, P.E., Boerman, R.H., ter Laak, H.J. and van Engelen, B.G. (2002) Concomitant Dermatomyositis and Myasthenia Gravis Presenting with Respiratory Insufficiency. Muscle \& Nerve, 25, 293296. http://dx.doi.org/10.1002/mus.10022

[3] Asakawa, H., Kashihara, T., Fukuda, H. and Yamamoto, M. (2002) A Patient with Thymoma and Four Different OrganSpecific Autoimmune Diseases. The Netherlands Journal of Medicine, 60, 292-295.

[4] Han, Y.S., Kim, B.H., Kim, T.H., Dong, S.H., Kim, H.J., Chang, Y.W., et al. (2000) Autoimmune Hepatitis in a Patient with Myasthenia Gravis and Thymoma-A Report on the First Case in Korea. The Korean Journal of Internal Medicine, 15, 151-155.

[5] Meguro, T., Nakamura, Y., Miura, K., Yamada, I., Okumura, M. and Harada, H. (2002) Autoimmune Hepatitis, Basedow's Disease and Myasthenia Gravis. The Journal of the Japanese Society of Internal Medicine, 91, 3507-3509. http://dx.doi.org/10.2169/naika.91.3507

[6] Kikuchi, H., Hayashi, N., Nakajima, T., Kuboi, H., Tokusige, K., Kubo, S., et al. (1988) A Case Report of Autoimmune Hepatitis with Myasthenia Gravis. The Japanese Journal of Gastro-Enterology, 85, 2261-2264.

[7] Taddy, H., Yoshida, E.M., Gibson, G. and Chatur, N. (2010) Acetylcholine Receptor Antibody Positive Generalized Myasthenia Gravis in Association with Primary Biliary Cirrhosis. Annals of Hepatology, 9, 471-472.

[8] Horigome, H., Nomura, T., Saso, K., Joh, T., Ohara, H., Akita, S., et al. (2000) Coexistence of Primary Biliary Cirrhosis and Myasthenia Gravis: A Case Study. Hepato-Gastroenterology, 47, 125-127.

[9] Marcus, S.N., Chadwick, D. and Walker, R.J. (1984) D-Penicillamine-Induced Myasthenia Gravis in Primary Biliary Cirrhosis. Gastroenterology, 86, 166-168.

[10] Finsterer, J. and Höflich, S. (2012) Long-Term, Low-Dose Immunosuppression for Myasthenia Does Not Affect Collateral Asymptomatic Sclerosing Cholangitis. Arquivos de Neuro-Psiquiatria, 70, 158-159. 
http://dx.doi.org/10.1590/S0004-282X2012000200019

[11] Korkmaz, H., Bugdaci, M.S., Temel, T., Dagli, M. and Karabagli, P. (2013) Autoimmune Hepatitis-Primary Biliary Cirrhosis Overlap Syndrome Concomitant with Immune Hemolytic Anemia and Immune Thrombocytopenic Purpura (Evans Syndrome). Clinics and Research in Hepathology and Gastroenterology., 37, e45-e50. http://dx.doi.org/10.1016/j.clinre.2012.11.001

[12] Alverez, F., Berg, P.A., Bianchi, F.B., Bianchi, L., Burroughs, A.K., Cancado, E.L., et al. (1999) International Autoimmune Hepatitis Group Report; Review of Criteria for Diagnosis of Autoimmune Hepatitis. Journal of Hepatology, 31, 929-938. http://dx.doi.org/10.1016/S0168-8278(99)80297-9

[13] Hennes, E.M., Zeniya, M., Czaja, A.J., Pares, A., Dalekos, G.N., Krawitt, E.L., et al. (2008) Simplified Criteria for the Diagnosis of Autoimmune Hepatitis. Hepatology, 48, 169-176. http://dx.doi.org/10.1002/hep.22322

[14] Chazouilleres, O., Wendum, D., Serfaty, L., Montembault, S., Rosmorduc, O. and Poupon, R. (1998) Primary Biliary Cirrhosis-Autoimmune Hepatitis Overlap Syndrome: Clinical Features and Response to Therapy. Hepatology, 28, 296-301. http://dx.doi.org/10.1002/hep.510280203 